\title{
PERANCANGAN TATAKELOLA TEKNOLOGI INFORMASI UNTUK PENINGKATAN LAYANAN SISTEM INFORMASI KESEHATAN (STUDI KASUS DINAS KESEHATAN KABUPATEN JEPARA)
}

\author{
Buang Budi Wahono \\ Fakultas Sains dan Teknologi, Program Studi Teknik Informatika \\ Universitas Islam Nahdlatul Ulama Jepara \\ Email: budihono78@gmail.com
}

\begin{abstract}
ABSTRAK
Perkembangan teknologi saat ini tak bisa dibendung lagi. Kemajuan disetiap bidang tak lepas dari teknologi sebagai penunjangnya, terutama teknologi informasi. Namun sebelum perluasan penggunaan, tentunya perlu sebuah evaluasi ataupun audit tatakelola teknologi inforrmasi yang ada. Untuk membangun dan mengembangkan sistem informasi dan dokumentasi ini diperlukan pengelolaan data yang baik. Penelitian ini bertujuan mengetahui sejauh mana pengelolaan data untuk layanan publik yang telah diterapkan pada Dinas Kesehatan Kabupaten Jepara dan memberikan rekomendasi tatakelola yang seharusnya di masa mendatang setelah mengetahui kesenjangan antara tatakelola saat ini dengan tatakelola yang diharapkan sesuai dengan framework yang digunakan. Framework yang digunakan dalam penelitian ini adalah COBIT versi 4.1 pada domain Deliver and Support (DS) khususnya DS11 yaitu manajemen data dan proses kontrol yang berhubungan, yaitu PO2 (Define the Information Architecture), DS4 (Ensure Continuous Service), DS5 (Ensure Systems Security) dan DS13 (Manage Operations). Dari hasil uji ini dapat diambil kesimpulan bahwa PO2 berpengaruh signifikan terhadap DS11, AI4 tidak berpengaruh signifikan terhadap DS11, DS1 berpengaruh signifikan terhadap DS11, DS4 berpengaruh signifikan terhadap DS11, DS5 berpengaruh signifikan terhadap DS11, DS11 tidak berpengaruh signifikan terhadap DS13, DS11 berpengaruh signifikan terhadap ME1.
\end{abstract}

Kata kunci: keterbukaan informasi publik; tatakelola teknologi informasi; COBIT, manajemen data.

\section{ABSTRACT}

The development of today's technology is not irreversible. Progress in every field can not be separated from technology as supporting, especially information technology. However, before the expansion of the use, of course, need an evaluation or audit governance inforrmasi existing technology. To build and develop the information system and documentation required good data management. This study aims to determine the extent of data management for Health Information System that have been applied to the Jepara District Health Office and provide governance recommendations that should be in the future after knowing the gap between the current governance with governance are expected according to the framework used. Framework used in this study is COBIT 4.1 version on the domain Deliver and Support (DS) especially DS11 is managing data and associated control process, ie PO2 (Define the Information Architecture), DS4 (Ensure Continuous Service), DS5 (Ensure Systems Security) and DS13 (Manage Operations). From the results of this test can be concluded that the PO2 significant effect on DS11, AI4 no significant effect on DS11, DS11 DS1 significant effect on, a significant effect on DS11 DS4, DS5 significant effect on DS11, DS11 no significant effect on DS13, DS11 significant effect on ME1.

Keywords: public information; governance of information technology; COBIT, data management.

\section{PENDAHULUAN}

\subsection{Sistem Informasi Kesehatan Dinas Kesehatan Kabupaten Jepara}

Sistem informasi kesehatan (SIK) merupakan aplikasi pengelolaan data kesehatan yang dikelola Dinas Kesehatan Kabupaten Jepara sebagai penjabaran Kepmenkes No.004/Menkes/SK/I/2003 tentang kebijakan \& strategi desentralisasi bidang kesehatan [1] dan Kepmenkes No.932/ Menkes/SK/VIII/2002 tentang petunjuk pelaksanaan pengembangan sistem laporan informasi kesehatan kabupaten/kota [2].

Saat ini SIK telah mengalami perkembangan yang sangat pesat, baik perkembangan dalam bidang software, hardware, serta kemampuan petugas. Software SIK sampai saat ini mampu mendukung kegiatan loket pendaftaran puskesmas sehingga riwayat sakit penderita beserta keluarga dapat terekam dengan baik dan mudah dicari apabila dibutuhkan. Diagnosa dan perintah pengobatan dimasukkan dalam basisdata di ruang pemeriksaan dan saat itu juga petugas apotik dapat menyiapkan obat pasien. 
Semua kegiatan di atas tidak hanya berlangsung di puskesmas saja namun sub unit seperti PKD, Puskesmas keliling, dan Puskesmas Pembantu juga di wajibkan untuk meng-entry-kan datanya, sehingga tercipta data yang acuntable, akurat dan tepat waktu yang akhirnya mampu mendukung pengambilan keputusan yang berkualitas pula.

Software SIK telah mengalami beberapa pengembangan. Dari versi SIK 1.0 dikembangkan menjadi SIK 2.0 dan saat ini sedang dikembangkan SIK 3.0 yang didalamnya ditambahkan modul PWS KIA yang akan memantau kegiatan kesehatan ibu dan anak di posyandu mengenai imunisasi, gizi dan penimbangan balita, pelayanan persalinan, nifas dan neonatus. PWS KIA akan mencakup semua catatan pelayanan tenaga kesehatan yang diberikan kepada pasien sejak lahir, neonatus, bayi, balita, usia SD, remaja, imunisasi calon pengantin, hamil, melahirkan, nifas, KB dan manula.

\subsection{Tatakelola Teknologi Informasi (IT Governance)}

Tatakelola teknologi informasi dibutuhkan karena selama ini pengambilan keputusan teknologi informasi di dewan direksi sering bersifat $a d h o c$ atau tidak terencana dengan baik [3]. Hal ini ditujukan denga fakta antara lain:

1. Keputusan dibuat dalam posisi perdebatan informal

2. Proyek disetujui tanpa konteks strategik

3. Fokus lebih pada kapasitas CIO dibandingkan tatakelola teknologi informasi berada pada jalurnya

4. Komunikasi dan presentasi dilakukan dengan bahasa yang terlalu technology minded.

5. CIO memiliki akuntabilitas di luar kendalinya

6. Dewan direksi terlalu fokus pada hal-hal kecil dibandingkan pada masalah yang lebih besar dari teknologi informasi.

Supaya keputusan teknologi informasi di level korporat dapat berjalan dengan benar maka perlu dibuatkan suatu sistem tatakelola teknologi informasi yang baik[4]. Sebagai aset khusus yang bernilai mahal dan mengandung resiko tinggi, teknologi informasi membutuhkan tatakelola yang baik agar proses keselarasan dengan seluruh strategi bisnis dapat mencapai tujuan organisasi. Untuk mewujudkan hal tersebut membutuhkan best practice tatakelola teknologi informasi yang meliputi kerangka kerja pada level puncak, jaminan dependensi antar unit dengan manajemen puncak, manajemen sumberdaya, manajemen resiko, keselarasan strategi dan pelaporan pengukuran konerja.

Tatakelola mempunyai cakupan lebih luas dibanding mengatur. Bank dunia mendefinisikan tatakelola sebagai pelaksanaan otoritas politis dan penggunaan sumber-sumber daya institusional untuk mengelola permasalahan-permasalahan dan urusan-urusan masyarakat. Definisi lainnya dari tatakelola adalah penggunaan institusi, struktur-struktur otoritas dan bahkan kolaborasi untuk mengalokasikan sumber-sumber data dan mengkoordinasi atau mengendalikan aktivitas masyarakat [4].

The IT Governance Institute (ITGI) mendefinisikan tatakelola teknologi informasi sebagai bagian integral dari tatakelola perusahaan yang terdiri atas kepemimpinan, struktur dan proses organisasional yang memastikan bahwa teknologi informasi organisasi berlanjut serta meningkatkan tujuan dan strategi organisasi [5]. Sementara itu Weill dan Ross (2004) sebagaimana dikutip dari Jogiyanto (2011), mendefinisikan tatakelola teknologi informasi sebagai penspesifikasian hak keputusan dan kerangka akuntabilitas untuk mengarahkan perilaku yang diinginkan dalam penggunaan teknologi informasi [6]. Ditegaskan juga bahwa tatakelola teknologi informasi tidak sekedar tentang pembuatan keputusan spesifik tetapi lebih pada penentuan siapa yang secara sistematis membuat dan berkontribusi pada keputusan tersebut.

Salah satu tujuan teknologi informasi adalah mengarahkan perilaku personel teknologi informasi yang diinginkan untuk mencapai tujuan organisasi yang efisien dan efektif. Tatakelola teknologi informasi sebagai sebuah sistem juga dapat diurai dan dijelaskan dari perspektif struktur. Struktur tatakelola teknologi informasi menunjukkan komponen yang membangun sistem tatakelola teknologi informasi, yaitu archetype, aktiva manusia, kendali dan regulasi.

Archetype menunjukkan struktur hak keputusan dan akuntabilitas pembuatan keputusan terkait tatakelola teknologi informasi. Archetype menunjukkan siapa yang memiliki hak dan besarnya proporsi keputusan yang terkait dengan tatakelola teknologi informasi.

Aktiva manusia menunjukkan para pihak yang terlibat dalam proses perancangan, implementasi, dan pengawasan sistem tatakelola teknologi informasi. Komponen ini lebih mengarah pada peran dan fungsi masingmasing pihak dalam sistem tatakelola teknologi informasi.

Kendali dan regulasi menunjukkan seperangkat aturan yang menjadi persyaratan agar diadopsi oleh organisasi yang menerapkan sistem tatakelola teknologi informasi. Komponen ini bersifat best practice yang dibangun oleh lembaga dan menjadi penduan bagi organisasi dalam mengembangkan sistem tatakelola teknologi informasi. Sebagai sebuah proses, tatakelola teknologi informasi dapat dilihat dari peran dan fungsi masing-masing komponen yang membentuk struktur tatakelola teknologi informasi.

Tatakelola Teknologi Informasi telah banya dikembangkan. Standard tools tersebut dikembangkan sebagai framework yang disusun berdasarkan best pratices dari hasil riset serta pengalaman bertahun-tahun dalam kegiatan audit teknologi informasi. Framework tersebut tentunya mengalami penyempurnaan yang berkelanjutan sebagai 
upaya menciptakan standar yang semakin baik, efektif dan efisien [7]. Berikut ini adalah beberapa standard tools/ framework yang banyak digunakan di dunia:

1. COBIT (Control Objectives for Information and related Technology)

2. COSO (Committee of Sponsoring Organisations of the Treadway Commission) Internal Control— Integrated Framework

3. ITIL (Information Technology Infrastructure Library)

4. ISO/IEC 17799

5. SOX

6. FIPS PUB 200

7. ISO/IEC TR 13335

8. ISO/IEC 15408:2005/Common Criteria/ITSEC

9. PRINCE2

10. PMBOK

11. TickIT

12. CMMI

13. TOGAF 8.1

14. IT Baseline Protection Manual

\section{$1.3 \mathrm{COBIT}$}

COBIT adalah best practice untuk manajemen teknologi informasi yang disusun oleh Information Systems Audit and Control Association (ISACA) dan IT Governance Institute (ITGI) yang pertama kali dirilis pada tahun 1996. Misinya adalah untuk meneliti, mengembangkan, mempublikasikan dan mempromosikan kewenangan, pembaruan, dan seperangkat pedoman umum yang diterima secara internasional untuk tujuan pengendalian teknologi informasi dalam penggunaan sehari-hari ileh para manajer bisnis dan auditor (Jogiyanto, 2011).

Target pengguna dari framework COBIT adalah organisasi / perusahaan dari berbagai latar belakang dan para profesional external assurance. Secara manajerial target pengguna COBIT adalah manajer, pengguna dan profesional teknologi informasi serta pengawas / pengendali profesional. Secara resmi tidak ada sertifikasi profesional resmi yang diterbitkan oleh ITGI atau organisasi manapun sebagai penyusun standar COBIT. Di Amerika Serikat standar COBIT sering digunakan dalam standar sertifikasi Certified Public Accountants (CPAs) dan Chartered Accountants (CAs) berdasarkan Statement on Auditing Standards (SAS) No. 70 Service Organisations review, Systrust certification or Sarbanes-Oxley compliance. Sertifikasi non COBIT yang merupakan pengakuan profesional auditor teknologi informasi diterbitkan oleh ISACA, sebagai afiliasi ITGI yaitu Certified Information Systems Auditor (CISA®) dan Certified Information Security Manager ${ }^{\circledR}$ (CISM®). Dalam sistem tatakelola TI, COBIT membagi tata kelola kedalam 34 proses yang dikategorikan dalam empat domain yang kemudian dijabarkan lagi menjadi 35 control process. Setiap control process akan diukur tingkat masing-masing menggunakan maturity model [8].

Maturity model adalah suatu metode untuk mengukur level pengembangan manajemen proses, yang berarti adalah mengukur sejauh mana kapabilitas manajemen tersebut. Seberapa bagusnya pengembangan atau kapabilitas manajemen tergantung pada tercapainya tujuan-tujuan COBIT.

Penerapan yang tepat pada tata kelola teknologi informasi di suatu lingkungan Enterprise, tergantung pada pencapaian tiga aspek maturity, yaitu kemampuan, jangkauan dan kontrol. Peningkatan maturity akan mengurangi resiko dan meningkatkan efisiensi, mendorong berkurangnya kesalahan dan meningkatkan kuantitas proses yang dapat diperkirakan kualitasnya dan mendorong efisiensi biaya terkait dengan penggunaan sumber daya teknologi informasi. Tingkat kemampuan pengelolaan teknologi informasi pada skala maturity dibagi menjadi 6 level :

1. Level 0 (Non-existent): perusahaan tidak mengetahui sama sekali proses teknologi informasi di perusahaannya

2. Level 1 (Initial Level) pada level ini, organisasi pada umumnya tidak menyediakan lingkungan yang stabil untuk mengembangkan suatu produk baru. Pengembangan sistem sangat tergantung pada satu individu sebagai keahlian perorangan dan belum sepenuhnya diakui sebagai kebutuhan perusahaan.

3. Level 2 (Repeatable Level): pada level ini, kebijakan untuk mengatur pengembangan suatu proyek dan prosedur dalam mengimplementasikan kebijakan tersebut telah ditetapkan. Tingkat efektifitas suatu proses manajemen dalam mengembangankan proyek adalah telah diakui sebagai kebutuhan institusi, dengan memungkinkan organisasi untuk mengulangi pengalaman yang berhasil dalam mengembangkan proyek sebelumnya, walaupun terdapat proses tertentu yang tidak sama. Tingkat efektifitas suatu proses mempunyai karakteristik seperti; practiced, dokumentasi, enforced, trained, measured, dan dapat ditingkatkan. Product requirement dan dokumentasi perancangan selalu dijaga agar dapat mencegah perubahan yang tidak diinginkan.

4. Level 3 (Defined Level): pada level ini, proses standar dalam pengembangan suatu produk baru didokumentasikan, proses ini didasari pada proses pengembangan produk yang telah 
diintegrasikan. Proses-proses ini digunakan untuk membantu manejer, ketua tim dan anggota tim pengembangan sehingga bekerja dengan lebih efektif. Suatu proses yang telah didefenisikan dengan baik mempunyai karakteristik; readiness criteria, inputs, standar dan prosedur dalam mengerjakan suatu proyek, mekanisme verifikasi, output dan kriteria selesainya suatu proyek. Aturan dan tanggung jawab yang didefinisikan jelas dan dimengerti. Karena proses perangkat lunak didefinisikan dengan jelas, maka manajemen mempunyai pengatahuan yang baik mengenai kemajuan proyek tersebut. Biaya, jadwal dan kebutuhan proyek dalam pengawasan dan kualitas produk yang diawasi.

5. Level 4 (Managed Level): Pada level ini, organisasi membuat suatu matrik untuk suatu produk, proses dan pengukuran hasil. Proyek mempunyai kontrol terhadap produk dan proses untuk mengurangi variasi kinerja proses sehingga terdapat batasan yang dapat diterima.

6. Level 5 (Optimized Level): Pada level ini, seluruh organisasi difokuskan pada proses peningkatan secara terus-menerus. Teknologi informasi sudah digunakan terintegrasi untuk otomatisasi proses kerja dalam perusahaan, meningkatkan kualitas, efektifitas, serta kemampuan beradaptasi perusahaan. Tim pengembangan produk menganalisis kesalahan untuk menentukan penyebab kesalahannya. Proses pengembangan melakukan evaluasi untuk mencegah kesalahan yang telah diketahui agar tidak terjadi lagi.

\section{METODOLOGI PENELITIAN}

\subsection{Pengumpulan Data}

Data yang digunakan dalam penelitian ini adalah data primer dan data sekunder. Data primer adalah data yang diperoleh langsung di lapangan. Sedangkan data sekunder adalah data yang diperoleh dari sumbersumber yang telah ada. Teknik pengambilan data dalam penelitian ini adalah survei dan pengambilan data melalui basis data. Metode pengambilan sampelnya menggunakan metode Purposive Judment Sampling. Pemilihan metode ini dikarenakan penelitian ini telah mempunyai sasaran dengan kriteria tertentu [9], yaitu menggunakan tabel RACI sesuai dengan standar Cobit [10]. Penelitian dilaksanakan dengan menggunakan instrumen penelitian yang terdiri dari observasi, wawancara, dan kuesioner untuk mengumpulkan bukti audit.

\subsubsection{Wawancara}

Wawancara dilakukan langsung dengan Kepala Sub Bagian Perencanaan Dan Evaluasi Dinas Kesehatan Kabupaten Jepara, untuk memperoleh gambaran secara rinci mengenai sistem yang berjalan pada Dinas Kesehatan Kabupaten Jepara sebagaimana pada Tabel 1.

Tabel 1. Sampel Wawancara sesuai Tabel RACI

\begin{tabular}{clll}
\hline No. & \multicolumn{1}{c}{ RACI Respondent } & \multicolumn{1}{c}{ Actual Respondent } & Jumlah \\
\hline 1. & Chief Information Officer & Ka. Sub Bag. Renval & 1 \\
\hline 2. & Business Process Owner & Kepala Kepegawaian & 1 \\
\hline 3. & Head Development & Koordinator Sistem Informasi & 1 \\
\hline 4. & Chief Architect & Pengelola Service \& Operation & 5 \\
\hline 5. & Head Operation & \\
\hline 6. & Head IT Administrator & Pengelola Quality Assurance & 2 \\
\hline 7. & Compliance, Audit, Risk and & & \\
\hline
\end{tabular}

\subsubsection{Kuesioner}

Kuesioner yang digunakan merupakan kuesioner checklist yang terdiri dari 113 pertanyaan mengenai aktivitas-aktivitas pada proses-proses TI pada proses DS11, PO2, AI4, DS1, DS4, DS5, Ds13, dan ME1. Responden mengisi kuesioner dengan mencantumkan check point pada skala yang terdapat pada setiap pertanyaan. Hasil penelitian digunakan sebagai bahan evaluasi. Evaluasi dilakukan untuk menentukan tingkat kematangan (maturity level) pengelolaan sistem informasi, khususnya manajemen data. Berdasarkan hasil kuesioner, maka 
dibuatlah pemetaan terhadap posisi tiap-tiap proses sistem informasi perusahaan terhadap model maturity. Adapun cara yang digunakan dalam melaksanakan penilaian maturity adalah dekomposisi deskripsi maturity menjadi beberapa pernyataan sehingga manajemen dapat memberikan tingkat persetujuannya [11]. Langkah-langkah untuk mengukur maturity model adalah sebagai berikut:

1. Rentang jawaban dibagi ke dalam empat skala yaitu: $1-2-3-4$ dengan nilai pemenuhan (compliance value) terhadap masing-masing skala yaitu $0-0,33-0,66-1$ sebagaimana pada tabel 2 .

Tabel 2. Nilai Pemenuhan

\begin{tabular}{clc}
\hline Skala & \multicolumn{1}{c}{ Aggrement with Statement } & Compliance value \\
\hline 1 & Not at all & 0 \\
\hline 2 & A little & 0,33 \\
\hline 3 & Quite a lot & 0,66 \\
\hline 4 & Completely & 1 \\
\hline
\end{tabular}

2. Nilai pemenuhan dari masing-masing level atas setiap jawaban dari pernyataan yang diberikan dijumlah kemudian dihitung perolehan maturity level compliance value dengan cara membagi total nilai pemenuhan dari setiap level [A] dengan jumlah pernyataan yang diberikan [B].

3. Setiap angka pada maturity level compliance value [C] kemudian dibagi dengan total keseluruhan perolehan maturity level compliance value, sehingga akan diperoleh normalized maturity level compliance value.

4. Setiap maturity level $[\mathrm{M}]$ kemudian dikalikan dengan normalized maturity level compliance value dari masing-masing maturity level [D] sehingga nantinya akan diperoleh nilai kontribusi untuk setiap maturity level.

\section{HASIL PENELITIAN DAN PEMBAHASAN}

\subsection{Analisis Deskriptif}

Dinas Kesehatan Kabupaten Jepara merupakan badan publik dibawah Pemerintah Kabupaten Jepara yang secara langsung menangani hal yang berhubung kait dengan kesehatan di wilayah Kabupaten Jepara. Unit Pelaksana Teknis yang berada dibawah koordinasi Dinas Kesehatan meliputi Gudang Farmasi, dan 21 Puskesmas di wilayah Kabupaten Jepara. Sistem informasi untuk publik yang ada belum terintegrasi dan disebarluaskan dengan baik. Pejabat Pengelola Informasi dan Dokumentasi (PPID) belum ditunjuk.

Menurut Pasal 1 Poin ke-9, Pejabat Pengelola Informasi dan Dokumentasi adalah pejabat yang bertanggung jawab di bidang penyimpanan, pendokumentasian, penyediaan, dan/ atau pelayanan informasi di Badan Publik [12], dan pada pasal 13 ayat (1) disebutkan bahwa untuk mewujudkan pelayanan cepat, tepat, dan sederhana setiap badan publik menunjuk Pejabat Pengelola Informasi dan Dokumentasi [13]. Namun PPID sampai sekarang belum ditunjuk.

Pengelola sistem informasi saat ini berada dibawah Sub Bagian Perencanaan dan Evaluasi (Renval). Sistem informasi yang sudah berjalan diantaranya Sistem Informasi Kesehatan (SIK) yang menjadi sarana pelaporan bagi pelayanan harian Puskesmas-Puskesmas di Kabupaten Jepara. Seluruh Puskesmas telah terhubung dengan jaringan server Dinas Kesehatan Kabupaten Jepara sehingga setiap hari semua kegiatan harian dapat dimasukkan secara online.

\subsection{Korelasi Bivariate}

Penelitian ini akan menguji hubungan masing - masing variabel secara terpisah dengan menggunakan uji statistik korelasi bivariate one tailed. Uji one-tailed dilakukan dengan asumsi bahwa hipotesis pada penelitian ini sudah diketahui arahnya.

Teknik ini dipilih untuk memberikan gambaran hubungan masing masing variabel sebagaimana digambarkan dalam model, walaupun teknik ini belum menghasilkan nilai pengaruh secara simultan antara variabel independent dan dependent [14]. 


\subsection{Pengolahan dan Analisis Data}

Setiap responden diberikan rangkaian pernyataan (sejumlah 45 pernyataan), masing-masing memberikan nilai sesuai nilai pemenuhan pada tabel 1 dan dilakukan perhitungan level maturity-nya sehingga didapat rata-rata level maturity. Nilai akhir yang diperoleh dari perhitungan menggambarkan perolehan nilai untuk perhitungan maturity level. Berdasarkan perhitungan level model maturity pada proses-proses yang diteliti, didapat hasil sebagai berikut:

Tabel 3. Maturity Level

\begin{tabular}{ccccccccc}
\hline Responden & PO2 & AI4 & DS1 & DS4 & DS5 & DS11 & DS13 & ME1 \\
\hline R1 & 3 & 2 & 3 & 2 & 2 & 3 & 2 & 2 \\
\hline R2 & 3 & 2 & 3 & 2 & 2 & 2 & 2 & 2 \\
\hline R3 & 3 & 2 & 3 & 2 & 2 & 3 & 2 & 2 \\
\hline R4 & 2 & 2 & 2 & 2 & 3 & 2 & 2 & 3 \\
\hline R5 & 2 & 3 & 2 & 3 & 3 & 2 & 3 & 3 \\
\hline R6 & 3 & 2 & 3 & 2 & 2 & 3 & 2 & 2 \\
\hline R7 & 2 & 3 & 2 & 3 & 3 & 2 & 3 & 3 \\
\hline R8 & 1 & 2 & 2 & 3 & 2 & 2 & 2 & 2 \\
\hline R9 & 2 & 2 & 2 & 3 & 3 & 2 & 3 & 3 \\
\hline R10 & 3 & 2 & 3 & 2 & 2 & 3 & 2 & 2 \\
\hline Global & 3 & 3 & 2 & 2 & 2 & 2 & 3 & 2 \\
\hline
\end{tabular}

Analisis korelasi Kendall's Tau dan Spearman adalah bagian dari Analisis Korelasi Bivariate, di mana analisis korelasi Kendall's Tau dan Spearman bertujuan mengukur hubungan dua variabel berdasarkan peringkat-peringkat. Analisis korelasi ini juga dimaksudkan untuk mengetahui hubungan antara dua variabel, keeratan hubungan, arah hubungan, dan apakah hubungan tersebut berarti atau tidak.[15]

Uji korelasi dimaksudkan untuk mengetahui tingkat keeratan hubungan yang dimiliki antar variabel dalam penelitian. Uji hubungan atau korelasi dapat dilakukan dengan beberapa metode hal ini tergantung jenis data yang digunakan.

Perbedaan antara Korelasi Spearman dan Kendall yakni jika dalam Korelasi Kendall (diberi symbol ĩ) merupakan suatu penduga tidak bias untuk parameter populasi, maka dalam korelasi spearman (diberi symbol r) dan tidak memberikan dugaan untuk koefisien peringkat suatu populasi. Dasar Pengambilan Keputusan dalam Uji Korelasi Spearman:

a) Jika nilai sig. < 0,05 maka, dapat disimpulkan bahwa terdapat korelasi yang signifikan antara variabel yang dihubungkan.

b) Sebaliknya, Jika nilai sig. > 0,05 maka, dapat disimpulkan bahwa tidak terdapat korelasi yang signifikan antara variabel yang dihubungkan.

Kriteria tingkat hubungan (koefisien korelasi) antar variabel berkisar antara $\pm 0,00$ sampai $\pm 1,00$. Tanda + adalah positif dan tanda - adalah negatif. Adapun kriteria penafsirannya adalah:

a) 0,00 sampai 0,20 , artinya : hampir tidak ada korelasi

b) 0,21 sampai 0,40 , artinya : korelasi rendah

c) 0,41 sampai 0,60 , artinya : korelasi sedang

d) 0,61 sampai 0,80, artinya : korelasi tinggi

e) 0,81 sampai 1,00, artinya : korelasi sempurna

Jika uji korelasi Spearman diadakan dengan SPSS maka langkah-langkahnya sebagai berikut:

1. Totalkan item-item variabel $\mathrm{x}$ menggunakan menu Transform $>$ Compute Variable $>$ jumlahkan item-item variabel $\mathrm{x}$.

2. Totalkan item-item variabel y menggunakan menu Transform $>$ Compute Variable $>$ jumlahkan item-item variabel y.

3. Buatlah Ranking bagi rx dan ry menggunakan menu Transform $>$ Compute $>$ Masukkan Skor Total Variabel X dan Variabel Y ke Variables > Pilih saja Smallest pada Assign Rank > Klik OK. Setelah itu muncul dua variabel baru yaitu rangking untuk x dan y (lihat di tab Variable View). 
4. Lakukan Uji Korelasi Spearman dengan SPSS dengan klik Analyze > Correlate > Bivariate > Masukkan Rangking X dan Ranking Y ke Variables > Pada Correlation Coefficient ceklis Spearman $>$ Pada Test of Significance pilih 2-Tailed (jika 2 sisi) atau 1-Tailed (jika 1 sisi) $>$ Klik OK.

Hasil dari uji yang dilakukan adalah sebagai berikut.

Tabel 4. Korelasi PO2-AI4-DS1-DS4-DS5-DS11 Spearman's rho

\begin{tabular}{|c|c|c|c|c|c|c|c|c|}
\hline & & & $\mathrm{PO} 2$ & AI4 & DS1 & DS4 & DS5 & $\overline{D S 11}$ \\
\hline \multirow[t]{18}{*}{$\begin{array}{l}\text { Spearman's } \\
\text { rho }\end{array}$} & \multirow{3}{*}{$\mathrm{PO} 2$} & $\begin{array}{l}\text { Correlation } \\
\text { Coefficient }\end{array}$ & 1 & $-0,385$ &, $962^{* *}$ &,$- 825^{* *}$ & $-0,629$ &, $786^{* *}$ \\
\hline & & Sig. (2-tailed) & . & 0,272 & 0 & 0,003 & 0,052 & 0,007 \\
\hline & & $\mathrm{N}$ & 10 & 10 & 10 & 10 & 10 & 10 \\
\hline & \multirow{3}{*}{$\mathrm{AI} 4$} & $\begin{array}{l}\text { Correlation } \\
\text { Coefficient }\end{array}$ & $-0,385$ & 1 & $-0,5$ & 0,612 & 0,612 & $-0,408$ \\
\hline & & Sig. (2-tailed) & 0,272 & & 0,141 & 0,06 & 0,06 & 0,242 \\
\hline & & $\mathrm{N}$ & 10 & 10 & 10 & 10 & 10 & 10 \\
\hline & \multirow{3}{*}{ DS1 } & $\begin{array}{l}\text { Correlation } \\
\text { Coefficient } \\
\end{array}$ &, $962^{* *}$ & $-0,5$ & 1 &,$- 816^{* *}$ &,$- 816^{* *}$ &, $816^{* *}$ \\
\hline & & Sig. (2-tailed) & 0 & 0,141 & & 0,004 & 0,004 & 0,004 \\
\hline & & $\mathrm{N}$ & 10 & 10 & 10 & 10 & 10 & 10 \\
\hline & \multirow{3}{*}{ DS4 } & $\begin{array}{l}\text { Correlation } \\
\text { Coefficient }\end{array}$ &,$- 825^{* *}$ & 0,612 &,$- 816^{* *}$ & 1 & 0,583 &,$- 667^{*}$ \\
\hline & & Sig. (2-tailed) & 0,003 & 0,06 & 0,004 & & 0,077 & 0,035 \\
\hline & & $\mathrm{N}$ & 10 & 10 & 10 & 10 & 10 & 10 \\
\hline & \multirow{3}{*}{ DS5 } & $\begin{array}{l}\text { Correlation } \\
\text { Coefficient } \\
\end{array}$ & $-0,629$ & 0,612 &,$- 816^{* *}$ & 0,583 & 1 &,$- 667^{*}$ \\
\hline & & Sig. (2-tailed) & 0,052 & 0,06 & 0,004 & 0,077 & & 0,035 \\
\hline & & $\mathrm{N}$ & 10 & 10 & 10 & 10 & 10 & 10 \\
\hline & \multirow{3}{*}{ DS11 } & $\begin{array}{l}\text { Correlation } \\
\text { Coefficient } \\
\end{array}$ &, $786^{* * *}$ & $-0,408$ &, $816^{* *}$ &,$- 667^{*}$ &,$- 667^{*}$ & 1 \\
\hline & & Sig. (2-tailed) & 0,007 & 0,242 & 0,004 & 0,035 & 0,035 & \\
\hline & & $\mathrm{N}$ & 10 & 10 & 10 & 10 & 10 & 10 \\
\hline
\end{tabular}

**. Correlation is significant at the 0.01 level (2-tailed).

*. Correlation is significant at the 0.05 level (2-tailed).

Table diatas menunjukkan bahwa koefisien korelasi antara semua proses terhadap DS11 (Manage Data) signifikan kecuali pada proses AI4 yang koefisien korelasinya hanya 0,408. Hal ini membuktikan bahwa PO2 (Define the Information Architecture), DS1(Define and Manage Service Levels), DS4 (Ensure Continuous Service), DS5 (Ensure Systems Security) dan DS13 (Manage Operations) berpengaruh signifikan terhadap DS11.

Tabel 5. Korelasi DS11-DS13-ME1 Spearman's rho

\begin{tabular}{|c|c|c|c|c|c|}
\hline & & & DS11 & DS13 & ME1 \\
\hline \multirow[t]{9}{*}{ Spearman's rho } & \multirow{3}{*}{ DS11 } & Correlation Coefficient & 1 & $-0,535$ &,$- 667^{*}$ \\
\hline & & Sig. (2-tailed) & . & 0,111 & 0,035 \\
\hline & & $\mathrm{N}$ & 10 & 10 & 10 \\
\hline & \multirow{3}{*}{ DS13 } & Correlation Coefficient & $-0,535$ & 1 &, $802^{* *}$ \\
\hline & & Sig. (2-tailed) & 0,111 & & 0,005 \\
\hline & & $\mathrm{N}$ & 10 & 10 & 10 \\
\hline & \multirow{3}{*}{ ME1 } & Correlation Coefficient &,$- 667^{\star}$ & ,802* & 1 \\
\hline & & Sig. (2-tailed) & 0,035 & 0,005 & \\
\hline & & $\mathrm{N}$ & 10 & 10 & 10 \\
\hline
\end{tabular}

Table diatas menunjukkan bahwa koefisien korelasi DS11 (Manage Data) terhadap ME1 (Monitor and Evaluate IT Performance) signifikan tetapi terhadap DS13 (Manage Operations) tidak signifikan. 
Tabel 6. Korelasi PO2-AI4-DS1-DS4-DS5-DS11 Kendall's tau

\begin{tabular}{|c|c|c|c|c|c|c|c|c|}
\hline & & & $\mathrm{PO} 2$ & Al4 & DS1 & DS4 & DS5 & DS11 \\
\hline & PO2 & & 1,000 &,- 371 &, $928^{* *}$ &,$- 796^{*}$ &,- 606 &, $758^{*}$ \\
\hline \multirow[t]{23}{*}{ tau_b } & & Coefficient & & & & & & \\
\hline & & Sig. (2-tailed) & & ,248 & ,004 &, 013 & ,059 &, 018 \\
\hline & & $\mathrm{N}$ & 10 & 10 & 10 & 10 & 10 & 10 \\
\hline & $\mathrm{Al} 4$ & Correlation &,- 371 & 1,000 &,- 500 & ,612 & ,612 &,- 408 \\
\hline & & Coefficient & & & & & & \\
\hline & & Sig. (2-tailed) & ,248 & &, 134 & ,066 & ,066 & ,221 \\
\hline & & $\mathrm{N}$ & 10 & 10 & 10 & 10 & 10 & 10 \\
\hline & DS1 & Correlation &, $928^{\star *}$ &,- 500 & 1,000 &,$- 816^{*}$ &,$- 816^{\star}$ &, $816^{*}$ \\
\hline & & Coefficient & & & & & & \\
\hline & & Sig. (2-tailed) &, 004 & ,134 & & ,014 & ,014 & ,014 \\
\hline & & $\mathrm{N}$ & 10 & 10 & 10 & 10 & 10 & 10 \\
\hline & DS4 & Correlation &,$- 796^{\star}$ & ,612 &,$- 816^{*}$ & 1,000 &, 583 &,$- 667^{*}$ \\
\hline & & Coefficient & & & & & & \\
\hline & & Sig. (2-tailed) &, 013 &, 066 &, 014 & & ,080 &, 046 \\
\hline & & $\mathrm{N}$ & 10 & 10 & 10 & 10 & 10 & 10 \\
\hline & DS5 & Correlation &,- 606 & ,612 &,$- 816^{*}$ &, 583 & 1,000 &,$- 667^{*}$ \\
\hline & & Coefficient & & & & & & \\
\hline & & Sig. (2-tailed) & ,059 &, 066 & ,014 &, 080 & & ,046 \\
\hline & & $\mathrm{N}$ & 10 & 10 & 10 & 10 & 10 & 10 \\
\hline & DS1 & Correlation &, $758^{*}$ &,- 408 &, $816^{*}$ &,$- 667^{*}$ &,$- 667^{\star}$ & 1,000 \\
\hline & 1 & Coefficient & & & & & & \\
\hline & & Sig. (2-tailed) & ,018 & ,221 & ,014 &, 046 &, 046 & \\
\hline & & $\mathrm{N}$ & 10 & 10 & 10 & 10 & 10 & 10 \\
\hline
\end{tabular}

Hasil olah data menggunakan Kendal's Tau juga menunjukkan menunjukkan hasil yang sama bahwa koefisien korelasi antara semua proses terhadap DS11 (Manage Data) signifikan kecuali pada proses AI4 yang koefisien korelasinya hanya 0,408. Hal ini membuktikan bahwa PO2 (Define the Information Architecture), DS1(Define and Manage Service Levels), DS4 (Ensure Continuous Service), DS5 (Ensure Systems Security) dan DS13 (Manage Operations) berpengaruh signifikan terhadap DS11.

Tabel 7. Korelasi DS11-DS13-ME1 Kendall's tau

\begin{tabular}{|c|c|c|c|c|c|}
\hline & & & DS11 & DS13 & ME1 \\
\hline \multirow[t]{9}{*}{ Kendall's tau_b } & DS11 & Correlation Coefficient & 1,000 &,- 535 &,$- 667^{*}$ \\
\hline & & Sig. (2-tailed) & & ,109 &, 046 \\
\hline & & $\mathrm{N}$ & 10 & 10 & 10 \\
\hline & DS13 & Correlation Coefficient &,- 535 & 1,000 &, $802^{*}$ \\
\hline & & Sig. (2-tailed) &, 109 & & ,016 \\
\hline & & $\mathrm{N}$ & 10 & 10 & 10 \\
\hline & ME1 & Correlation Coefficient &,$- 667^{*}$ &, $802^{*}$ & 1,000 \\
\hline & & Sig. (2-tailed) &, 046 &, 016 & \\
\hline & & $\mathrm{N}$ & 10 & 10 & 10 \\
\hline
\end{tabular}


Hasil olah data menggunakan Kendal's Tau juga menunjukkan menunjukkan hasil yang sama bahwa DS11 (Manage Data) terhadap ME1 (Monitor and Evaluate IT Performance) signifikan tetapi terhadap DS13 (Manage Operations) tidak signifikan.

Empat tabel di atas menunjukkan bahwa korelasi yang signifikan, yaitu dengan nilai Sig. (2-tailed) lebih kecil dari 0,05 terjadi pada PO2, DS1, DS4, maupun DS5 dengan DS11 serta DS11 dengan ME1. Hal ini terjadi pada Uji Spearman dan Uji Kendall. Dari hasil uji ini dapat diambil kesimpul sebagai berikut.
a) H1 diterima, jadi PO2 berpengaruh signifikan terhadap DS11
b) H2 ditolak, jadi AI4 tidak berpengaruh signifikan terhadap DS11
c) H3 diterima, jadi DS1 berpengaruh signifikan terhadap DS11
d) H4 diterima, jadi DS4 berpengaruh signifikan terhadap DS11
e) H5 diterima, jadi DS5 berpengaruh signifikan terhadap DS11
f) H6 ditolak, jadi DS11 tidak berpengaruh signifikan terhadap DS13
g) H7 diterima, jadi DS11 berpengaruh signifikan terhadap ME1

\section{KESIMPULAN}

Proses mengelola data (DS11) pada Dinas Kesehatan Kabupaten Jepara Jepara berada pada level 2 (Repeatable Level), dengan empat masukan berkorelasi secara signifikan, yaitu PO2, DS1, DS4, dan DS5 serta satu masukan tidak berkorelasi secara signifikan, yaitu AI4. Level 3 (Defined Process) merupakan level terdekat yang dapat dijadikan target peningkatan kemapanan proses mengatur data Dinas Kesehatan Kabupaten Jepara. Kondisi yang menjadi target adalah organisasi telah memiliki proses yang didokumentasikan dan dikomunikasikan.

Untuk meningkatkan tingkat kemapanan berdasarkan COBIT 4.1 dilakukan penentuan prioritas dan target dari perbaikan yang akan dilakukan. Peningkatan tingkat kemapanan tidak terlepas dari 6 atribut kematangan COBIT 4.1, yaitu Awareness and Communication (AC), Policies, Standards and Procedures (PSP), Tools and Automation (TA), Skill and Expertise (SE), Responsibilities and Accountabilities (RA), dan Goal Setting and Measurement (GSM). DS11 mempunyai lima proses masukan dan dua proses keluaran. Proses-proses yang berhubungan dengan DS11 ada satu masukan, yaitu AI4, yang tidak berkorelasi secara signifikan. Hal ini perlu menjadi bahan penelitian lanjutan untuk dicari penyebabnya.

\section{DAFTAR PUSTAKA}

[1] Kepmenkes No.004/Menkes/SK///2003 tentang kebijakan \& strategi desentralisasi bidang kesehatan

[2] Kepmenkes No.932/Menkes/SK/VIII/2002 tentang petunjuk pelaksanaan pengembangan sistem laporan informasi kesehatan kabupaten/kota.

[3] Alhan, M. 2011. "Perancangan IT Governance Menggunakan Cobit Versi 4.1". Jurnal Politeknosains 10.2, $11-22$.

[4] Jogiyanto. (2011). Sistem Tatakelola Teknologi Informasi. Yogyakarta: Andi Offset.

[5] Riyadi, K. 2009. “Usulan Perbaikan Tatakelola Teknologi Informasi BUMN”. Tesis Magister Electrical Engineering. Institut Teknologi Bandung.

[6] Weill, P., and Ross, J. (2004). IT Governance: How Top Performers Manage IT Decision Rights for Superior Results. Boston : Harvard Business School Press.

[7] Maniah, and Surendro, K. 2005. "Usulan Model Audit Sistem Informasi (Studi Kasus: Sistem Informasi Perawatan Pesawat Terbang)”. Prosiding Seminar Nasional Aplikasi Teknologi Informasi. E45 - E51.

[8] IT Governance Institute. COBIT 4.1. Control Objective for Information and Related Technology. USA:ITGI;2007.

[9] Ghozali, I. (2009). Aplikasi Analisis Multivariate Dengan Program SPSS, Semarang: Badan Penerbit Universitas Diponegoro.

[10] Surendro, K. 2008. "Rancangan Tatakelola Teknologi Informasi untuk Pabrik Pupuk". Jurnal Informatika 9.2. $115-121$.

[11] Effendi, D. 2008. "Perancangan IT Governance pada Layanan Akademik di Unikom (Universitas Komputer Indonesia) Menggunakan COBIT (Control Objectives for Information and Related Technology) Versi 4.0". Tesis Magister Informatics. Institut Teknologi Bandung. 
[12] Komarudin and Wahjono, H. 2008. "Implikasi Undang-Undang Nomor 14 Tahun 2008 tentang Keterbukaan Informasi Publik pada Informasi Teknologi Pengelolaan Air Bersih dan Limbah Cair”. JAI 4. 2, 173 - 183.

[13] Komarudin and Yudo S. 2009. “Aplikasi Undang-Undang Tentang Informasi dan Pelayanan Publik dalam Kasus Sistem Informasi Teknolgi Pengelolaan Air Bersih dan Limbah Cair”. JAI 5. 2, 190 - 204.

[14] Azwar, S. (2008). Reliabilitas dan Validitas, Yogyakarta: Pustaka Pelajar.

[15] Trihendradi, C. (2011). Langkah Mudah Melakukan Analisa Statistik Menggunakan SPSS 19. Yogyakarta: Andi Offset. 